\title{
SCIDoc

\section{Unusual Response of Human Tissue under the Low Impact Force}

Stojiljkovic $\mathrm{G}^{1 *}$, Papić $\mathrm{Z}^{2}$, Bogdanović $\mathrm{V}^{2}$, Simeunović $\mathrm{M}^{2}$, Saulić $\mathrm{N}^{2}$, Miljen $\mathrm{M}^{2}$

${ }^{1}$ University of Novi Sad, Faculty of Medicine, Institute of Forensic Medicine, Hajduk Veljkova, Novi Sad, Serbia.

${ }^{2}$ University of Novi Sad, Faculty of Technical Sciences, Department of Traffic Engineering, Trg Dositeja Obradovića, Novi Sad, Serbia.

\section{Abstract}

Pedestrian injuries such as traumatic amputations, transections and decapitations are rare in traffic accidents, but are directly connected to high vehicle impact speeds.

This paper analyses a unique case of a traumatic limb amputation and a lateral decapitation from a pedestrian car collision. The driver left the scene of the accident, but at the place of impact the car's registration plate was found. After identifying the driver and performing a vehicle inspection, it was determined that the damage on the car does not show that the impact speed was extremely high. The same conclusion was reached by the vehicle speed determination, according to accident investigation basic principles.

Keywords: Decapitation; Dismemberment; Pedestrian; Impact Speed.

\section{Introduction}

Pedestrians belong to the most vulnerable category of participants in road traffic accidents $[1,2]$. In this type of accident, one part of the energy coming from the vehicle during the crash phase is transferred to the human's body or tissue, causing the traumatic event [3]. The other part of the energy is transferred into the vehicle and thereby causing deformations of the vehicle itself $[4,5]$. Both the characteristics and the severity of pedestrian injuries and vehicle damage could be taken into account in order to get a rough vehicle impact speed estimation. By analysing some characteristic injuries from pedestrian car impacts, a relationship between the type of injuries and the impact speed was determined [6]. On the other hand, energy losses during impact, manifested as vehicle deformations, are in proportion to the vehicle impact speed. In most cases, pedestrian decapitations, trunk transections and limb amputations in vehicle crashes are a consequence of extremely high energy exchanges caused by the vehicle impact speed. According to Zivot and Di Maio [7], traumatic limb amputations or transections of the torso in car to pedestrian impacts, occur at impact speeds above $88.5 \mathrm{~km} / \mathrm{h}$. Dismemberment of the body, defined as a complete or incomplete severance of the trunk or neck, or a complete amputation of the leg, occurs at impact speeds above $98 \mathrm{~km} / \mathrm{h}[6]$. Pedestrian decapitations in road traffic accidents are exceptionally rare, but are directly related to high vehicle impact speeds [8].

This paper illustrates a unique accident where the pedestrian injuries indicate a high impact speed, but the damage to the vehicle does not indicate the same. According to the autopsy findings and the results of the accident investigation, this case report presents the possible explanation of the pedestrian's injury and the results of the vehicle impact speed calculations, performed by a technical expert.

\section{Materials and Methods}

A 52-year old male pedestrian was struck by a car as he was walking on a poorly lit street during the night. A part of the pedestrian's left lower leg was found $25 \mathrm{~m}$ from the point of impact and his head was found about $7 \mathrm{~m}$ away from the body. The place of impact was determined according to the concentration of dirt fragments that were found on the road, in front of all other traces. The position of the point of impact indicates that the pedestrian was hit before the driver of the vehicle slammed on the brakes. The vehicle left skid marks that were $21 \mathrm{~m}$ in length. In relation

\section{*Corresponding Author:}

Goran Stojiliković, MD, PhD,

University of Novi Sad, Faculty of Medicine, Institute of Forensic Medicine, Hajduk Veljkova 1, 21000 Novi Sad, Serbia.

Tel/Fax: +381216624141

Email: goran.stojiljkovic@mf.uns.ac.rs

Received: September 14, 2016

Accepted: October 12, 2016

Published: October 14, 2016

Citation: Stojiljkovic G, Papić Z, Bogdanović V, Simeunović M, Saulić N, et al., (2016) Unusual Response of Human Tissue under the Low Impact Force. Int J Forensic Sci Pathol. 4(10), 285-288. doi: http://dx.doi.org/10.19070/2332-287X-1600066

Copyright: Stojilikovic $\mathbf{G}^{\circ}$ 2016. This is an open-access article distributed under the terms of the Creative Commons Attribution License, which permits unrestricted use, distribution and reproduction in any medium, provided the original author and source are credited. 
to the point of impact, the pedestrian's body was thrown forward and toward the right side, approximately $31 \mathrm{~m}$ away. The driver fled the scene but near the pedestrian's body the vehicle registration plate was discovered, so he and the vehicle were easily identified. A sketch of the accident is shown in Figure 1.

\section{Vehicle Information and Inspection}

The investigation found that the vehicle which struck the pedestrian was a "Peugeot 206". On the front end of the car, there was visible damage on the lower part of the hood and under the right headlight, whose glass cover was broken. The right fender was damaged nearby the right edge of the headlight. The windshield was completely smashed from the base to the top right side. The damage was also visible on the right side of the vehicle, below the right A-pillar. The right side view mirror and the registration plate fell off during the impact and were found near the place of impact. On the right side of front bumper cover there was no visible damage or marks from the impact. Brain tissue was found on the windows on the right side of the car. The brain tissue extended from the front right A-pillar, fading to the back right part of the vehicle (Figure $2 \& 3$ ).

\section{Autopsy Findings}

The body of the 52-year old male pedestrian was $1.64 \mathrm{~m}$ in length. The left lower leg was dismembered $45 \mathrm{~cm}$ above the plane of the foot, and the left femur was broken. On the back of the right thigh, at $64 \mathrm{~cm}$ above the plane of the foot, there was a fracture of the femur found along with a massive hematoma of the soft tissue and split lacerations. The head was separated from the spinal column. The bones of the face and the skull were separated, and the lower jaw and facial bones were broken in multiple places. The majority of the brain tissue was missing. At the Adam's apple all neck organs were dissected. The bodies of the thoracic vertebrae of the neck from $7^{\text {th }}$ to $3^{\text {rd }}$ were disarticulated. Cervical extensions from $4^{\text {th }}$ to $9^{\text {th }}$ thoracic vertebrae were broken. Both blade bones and collarbones were broken in multiple places. All ribs on the right side were fractured at two lines (the front armpit and the line of the shoulder blade). All ribs on the left were fractured in conjunction with the spinal column and posterior axillary line. The liver tissue was torn, etc. The autopsy findings determined that the alcohol concentration in the pedestrian's blood was $0.2014 \%$.

\section{Discussion}

According to the vehicle deformations and the pedestrian's injuries, it was determined that the primary contact was made between the right side of the vehicle's front bumper, below the front right headlight, and the back and partly outer surface of the pedestrian's left lower leg which was firmly planted on the ground at the moment of contact. This impact resulted in a traumatic amputation of the left lower leg (Figure 4). In the second phase of impact, the pedestrian's body rotated clockwise and fell over the right half of the windshield and upper part of the front right pillar. At this point injuries in the form of fractures of the shoul-

Figure 1. Sketch of the Accident.

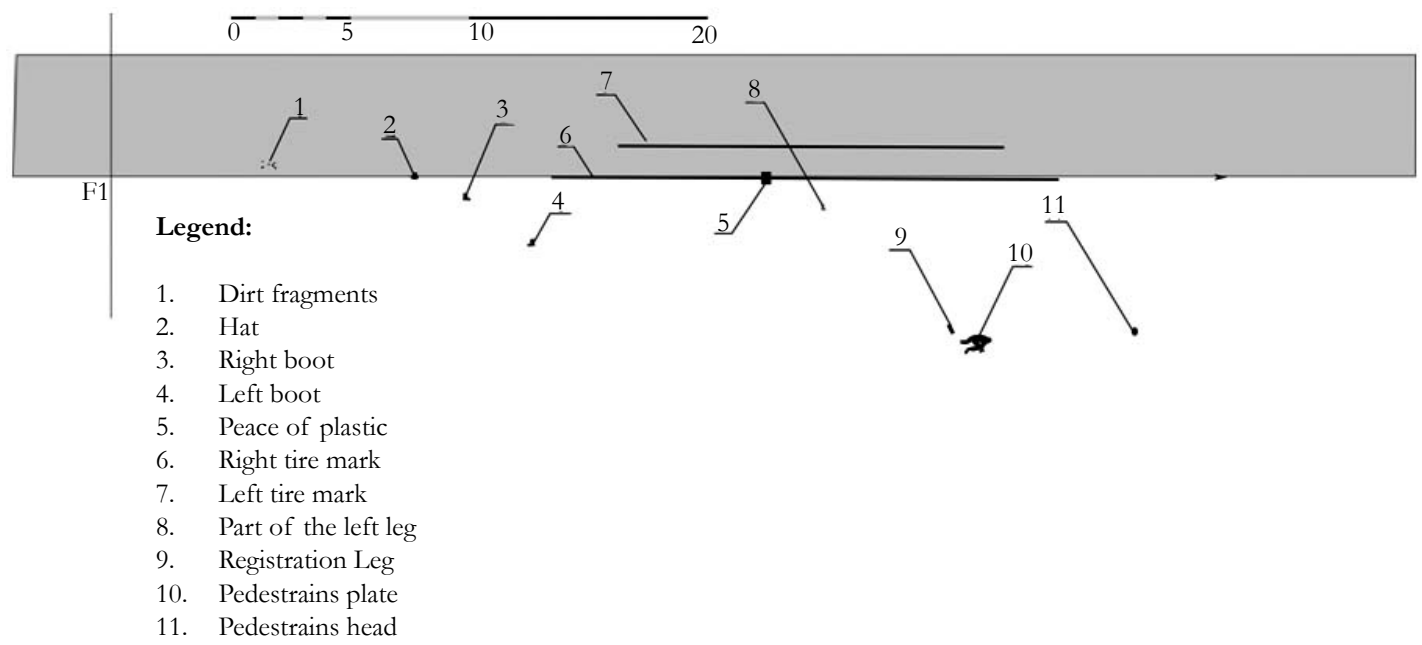

Figure 2. Brain Tissue Marks on the Right Side of the Vehicle.

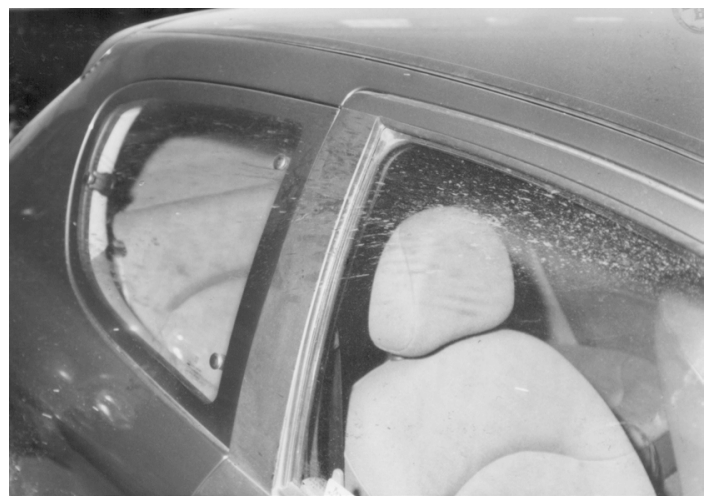


Figure 3. Front View of the Vehicle.

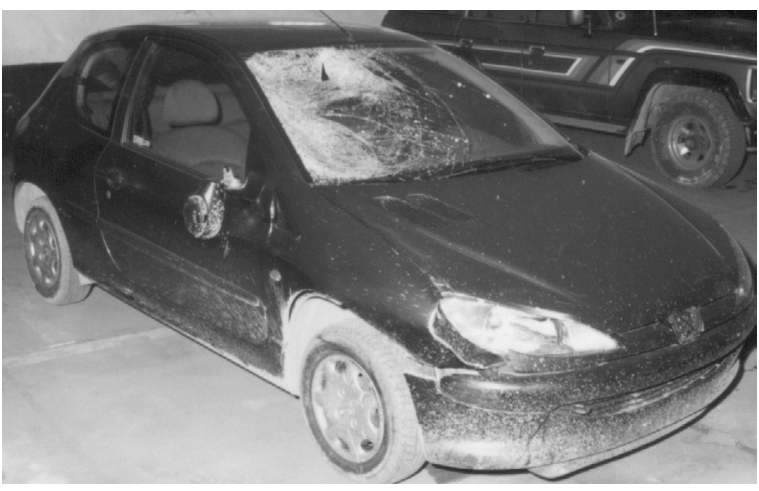

Figure 4. Part of the Left Lower Leg.

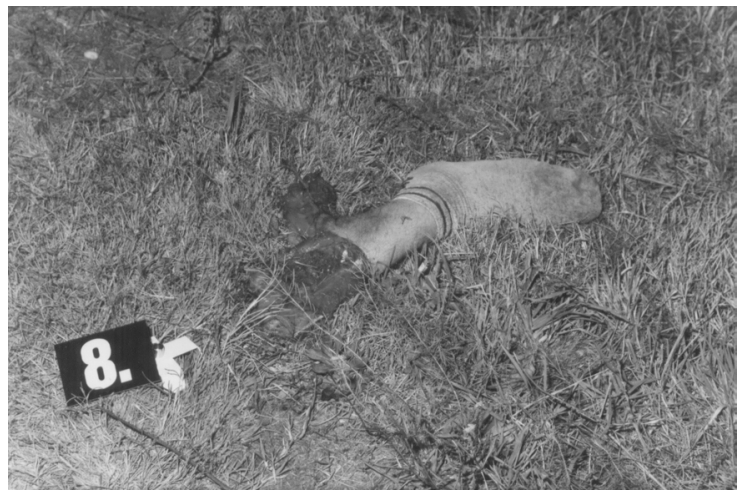

Figure 5. Pedestrian's Head.

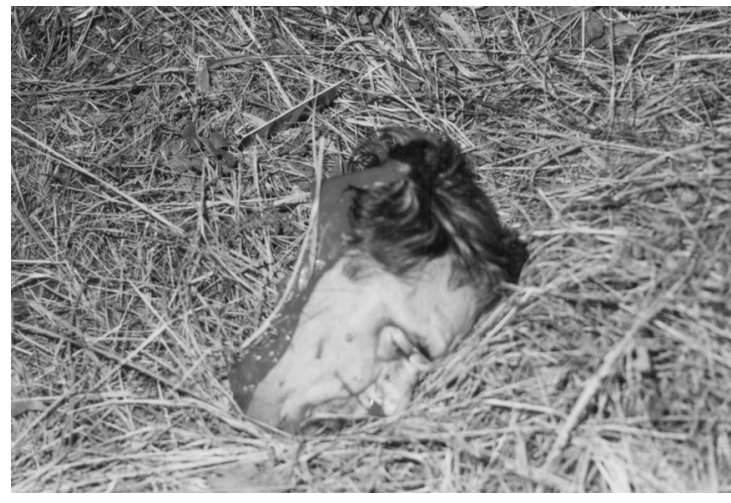

der blade bones, thoracic vertebrae, two-sided serial rib fractures, disarticulation of the cervical and thoracic spine and the separation of the skull from the body occurred (Figure 5). Some of the injuries could have incurred during the third phase of the impact, after contact with the ground or surrounding objects was made.

The severity and characteristics of the pedestrian's injuries in this case, indicate that the vehicle impact speed was high. In order to establish the relationship between the impact speed, injuries and distance thrown, Zivot and Di Maio [7] reviewed 85 fatal motor vehicle-pedestrian deaths. Five of the cases involved amputations of limbs, and two involved transections of the torso. In all seven cases, the vehicles impact speeds were minimum $88.5 \mathrm{~km} / \mathrm{h}$. Simular findings were reached by Teresinski [9] who concluded that limb amputations are indicators of impact speeds higher than 90 $\mathrm{km} / \mathrm{h}$. He also found that amputations could be produced even at velocities lower than $60 \mathrm{~km} / \mathrm{h}$, especially when the vehicle is not braking and lower limbs get trapped under the front bumper. De- capitations in road traffic accidents are extremely rare. Some of the cases of decapitation were described in motorcycle accidents [10-12] and car crashes [13, 14]. Decapitations in car-to-pedestrian impacts are mostly unheard of. On the vehicle exterior there are no sharp edges that could produce these kinds of injuries at lower impact speeds. A large part of the contact surface on the front side of the vehicle is a windshield, made from laminated safety glass, which could apsorb most of the impact energy. The only parts on the front side of the car which could cause injuries such as pedestrian decapitation are the roof and A-pillar edges.

Most equations that could be used for calculating speed in carto-pedestrian impact are based on the pedestrian throw distance. Some of those equations are empirical, as a results of experiments, and some of them are based on Newton's laws of mechanics. By applying the formula derived by Barzeley and Lacy [15], which could be used if the vehicle is not braking at or prior to impact, the vehicle impact speed as a function of the pedestrian throw 
distance, for this case was $68 \mathrm{~km} / \mathrm{h}$. In Searle's equation [16], the vehicle impact speed could be calculated by knowing the pedestrian throw distance and launch angle. Depending on the pedestrian launch angle value, it is possible to calculate the minimum and the maximum vehicle impact speed. As a friction coefficient value for wet or dry grass, he recommended 0.79. Using Searl's equations, the vehicle impact speed for this case was in the range of 49-79 $\mathrm{km} / \mathrm{h}$. In Wood's Single Segment Model (SSM) [17], for calculating of car-to-pedestrian impact speeds, besides knowing the distance the pedestrian was thrown from point of impact to point of rest, it is necessary to know the pedestrian's and vehicle's weight, and the height difference between the pedestrian's centre of mass [18] and the upper contact point on the vehicle front. The vehicle impact speed for the analysed case using Wood's formula was 76.5 $\mathrm{km} / \mathrm{h}$. According to Appel's [19] empirical formula which is also based on a pedestrian's throw distance, the vehicle impact speed was $75.8 \mathrm{~km} / \mathrm{h}$. A similar conclusion is reached by analyzing the damages on the vehicle. The head contact near the upper frame of the windshield with the significant deformation of the body panels occurred at an impact speed arround $70 \mathrm{~km} / \mathrm{h}[20]$.

Injuries and vehicle deformations are some of the indicators required for determining the speed of impact in collisions involving a car and a pedestrian. This case presents a traffic accident where the pedestrian's injuries were unique and not typical because of the traumatic amputation of the left lower leg caused by the bumper impact and the lateral decapitation emerged as a consequence of the pedestrian's head contact with the vehicle's roof and pillar edges. The severity of the pedestrian's injuries severity indicates that the vehicle impact speed was high and according to the former research it was not less than $88.5 \mathrm{~km} / \mathrm{h}$. By using five pedestrian throw models and the vehicle damage analysis for this case, it was concluded that the vehicle impact speed amounted to a maximum of $79 \mathrm{~km} / \mathrm{h}$. This indicates that the car-to-pedestrian impact speed shouldn't be easily estimated according to the severity of the injuries. Instead it should be determined through collaboration between the accident reconstructionists and medical forensic experts.

\section{References}

[1]. Kual A, Sinha US, Pathak YK, Singh A, Kapoor AK et al., (2005) Fatal road traffic accidents, study of distribution, nature and type of injury. JIAFM. 27: 71-76.
[2]. WHO. Pedestrian safety $-\mathrm{A}$ road safety manual for decision makers and practitioners, 2013.

[3]. NAEMT (2011) Pre-Hospital Trauma Life Support Committee: American College of Surgeons. Committee on Trauma. (7th edn), Burlington, US.

[4]. Burg H, Moser A (2009) Handbuch Verkehrsunfallrekonstruktion. Vieweg+Teubner, Verlag.

[5]. Xu J, Li Y, Lu G, Zhou W (2009) Reconstruction model of vehicle impact speed in pedestrian-vehicle accident. Int J Impact Eng. 36(6): 783-788.

[6]. Karger B, Teige K, Bühren W, DuChesne A (2000) Relationship between impact velocity and injuries in fatal pedestrian-car collisions. Int J Legal Med. 113(2): 84-88.

[7]. Zivot U, Di Maio VJM (1993) Motor vehicle-pedestrian accidents in adults: relationship between impact speed, injuries and distance thrown. Am J Forensic Med Pathol. 14(3): 185-186.

[8]. Behera C (2008) Decapitation with egg shelling of the skull in a road traffic accident. Med Sci Law. 48(1): 87-88.

[9]. Teresinski G, Madro R (2001) Ankle joint injuries as a reconstruction parameter in car-to-pedestrian accidents. Forensic Sci Int. 118(1): 65-73.

[10]. Zoja R, Gentile G, Giovanetti GF, Palazzo E (2011) Death by complete decapitation of motorcyclist wearing full face hellmet: Case report. Forensic Sci Int. 1016: 48-50.

[11]. Ihama Y, Miyazaki T, Fuke C, Niki H, Maehira T (2008) Complete decapitation of a motorcycle driver due to a roadblock chain. Int J Legal Med. 122(6): 84-88.

[12]. Hitosugi M, Motozawa Y, Nagai T, Tokodume S (2005) Decapitation in helmeted motorcyclist. Am J Forensic Med Pathol. 26(2): 198.

[13]. Rautji R, Rudra A, Dixit V, Bhardwaj DN, Dogra TD (2003) Decapitation in road traffic accident—a case report. Forensic Sci Int. 135(3): 237-238.

[14]. Kibayashi K, Yonemitsu K, Honjjyo K, Tsunenari S (1999) Accidental decapitation: an unusual injury to a passenger in a vehicle. Med Sci Law 39(1): 82-84.

[15]. Barzeley ME, Lacy GW (1991) Scientific Automobile Accident Reconstruction. Matthew Bender Publishing.

[16]. Searle JA, Searle A (1983) The Trajectories of pedestrians, motorcycles, motorcyclists etc. following a road accident. SAE Technical paper. 831622

[17]. Wood DP, Simms CK, Walsh DG (1999) Vehicle-pedestrian collisions: validate models for pedestrian impact and projection. Proc Inst Mech Eng D J Automob Eng 219 (2): 183-195.

[18]. Croskey MI, Dawson PM, Luessen AC, Marohn IE, Wright HE (1922) The height of the center of gravity in man. Am J Physiol. 61(1): 171-185.

[19]. Appel H, Sturtz G, Gotzen L (1975) Influence of Impact Speed and Vehicle Parameters on Injuries to Children and Adults in Pedestrian Accidents. IRCOBI. 3: 83-100.

[20]. Happer A, Arazewski M, Overgaard R, Toor A, Johal R (2000) Comprehensive Analysis Method for Vehicle/Pedestrian Collisions. SAE. 1: 846. 